\title{
VOLVER AL BOSQUE. NOSTALGIA, UTOPÍA Y JUEGO
}

\author{
Ana Esther Santamaría Fernández \\ Universidad Rey Juan Carlos de Madrid. Dpto Ciencias Jurídicas y Sociales
}

\section{Resumen}

El género del paisaje se consolidó con el arranque del mundo contemporáneo hasta convertirse en una de las vías más transitadas del terreno artístico. El paisaje está de moda y el bosque es uno de los espacios más aludidos en la escena artística. Baste recordar la proliferación de parques de esculturas situados en estas áreas frondosas. Pero, antes que analizar la capacidad museística del bosque, o su relación con la ciencia o los discursos que tratan de hacer del arte una bandera en pro de la sostenibilidad, los párrafos que siguen van a delinear los modos en que algunos creadores han vuelto al bosque, un argumento que tiene que ver con la relación emotiva que los individuos han venido estableciendo con este espacio a lo largo del tiempo.

\section{BACK TO THE FOREST NOSTALGIA, UTOPIA AND PLAY}

\section{Abstract}

The genre of the lanscape was consolidated with the start of the contemporary world to become one of the busiest roads of the artistic field. The landscape is fashionable and the forest is one of the most alluded spaces in the artistic scene. Suffice it to recall the proliferation of sculpture parks located in these leafy areas. But, before analyzing the museistic capacity of the forest, or its relationship with science or the discourses that try to make art a banner of sustainability,the paragraphs that follow are going to delineate the ways in which some creators have returned to the forest, an argument that has to do with the emotional relationship that individuals has been stablishing with this space over time.

Keywords: FOREST; LANSCAPE; GAME; UTOPIA; NOSTALGIA

\footnotetext{
Santamaría Fernández, Ana Esther. "Volver al bosque: Nostalgia, utopía y juego". AusArt 6 (1): 273-282. DOI: 10.1387/ausart.19470
}

\section{AUSART}


Irse al bosque, emboscarse, decía Ernst Jung en su libro La emboscadura no es una actividad idílica y sencilla. La denominación del bosque tampoco es diáfana, su semántica es compleja e imprecisa y son numerosas las palabras que se usan designarlo. Bosque es tanto un espacio indómito, un lugar ameno para el deleite o una espesura tenebrosa. Es madrastra hostil y madre fértil, nutricia y espiritual. Fuente de recursos y santuario. Vedado en el que habita la divinidad y lugar de desenfreno. Escondite para los proscritos y camino de búsqueda y hallazgo para los neófitos. Casa primera del hombre y tierra de nadie, es núcleo de la condición salvaje, margen de la civilización y origen inseparable de la misma.

En la tradición occidental la relación que los hombres tienen con el bosque es eminentemente bipolar. La dimensión salvaje del bosque queda contrarrestada con el afán de domesticación que viene de la cultura; la de lugar sagrado, con el utilitarismo y la de locus horridus con la de locus amoenus. Según el bosque desaparece debido al avance de la civilización, se potencian, sus dimensiones positivas y aumenta el interés por su custodia. Así, los parajes verdes se han convertido en un símbolo de naturaleza sin mancillar en los que la utopía contemporánea se torna verosímil. Cuestión que recogió Ernest Callenbach en Ecotopía (1975), que se convirtió en una novela de culto entre los ecologistas. El principal logro de la sociedad ecotopiana (en la que perviven la segregación racial y la agresividad), es que ha sido capaz de devolver a los bosques a una Edad de Oro primordial.

Pero, el anhelo de un estado primigenio ideal es nostalgia y no utopía, pues la utopíaes siempre porvenir y el Edén habita en la idea de un pasado originario, cuando hombre y naturaleza eran una sola cosa. A medida que el ser humano avanzaba hacia la civilización, se separaba del entorno salvaje y se gestaba en él una conciencia, cada vez más vaga, de aquello que había dejado atrás. El abandono del estado de naturaleza acompañado de un sentimiento nostálgico por la pérdida de algo que no se va a poder recuperar, es un lugar común en el acervo cultural de muchos pueblos. Casi todas las culturas albergan entre sus creencias la idea de que existe un lugar idílico, generalmente frondoso, en el que todos los aspectos penosos de la realidad no tienen cabida, pero al que no es fácil acceder.

Thomas Struth comenzó en 1998 a tomar fotografías de distintas selvas y bosques de Asia, América y Australia y las tituló New Picturesfrom Paradise. Espacios enmarañados que no permiten delimitar formas únicas porque son inabarcables en un golpe de vista, paraísos imposibles que no se dejan con- 
templar. Un extrañamiento similar muestra Axel Hütte en algunas de sus obras que muestran el bosque como un espacio sin hombres, que hablan de lo que no puede atraparse, de lo que no se ha visto, de lo incólume y desconocido. Son fragmentos de frágiles ensoñaciones, de lo que no puede ser, que no fue y que no será porque su acceso ha sido vetado.

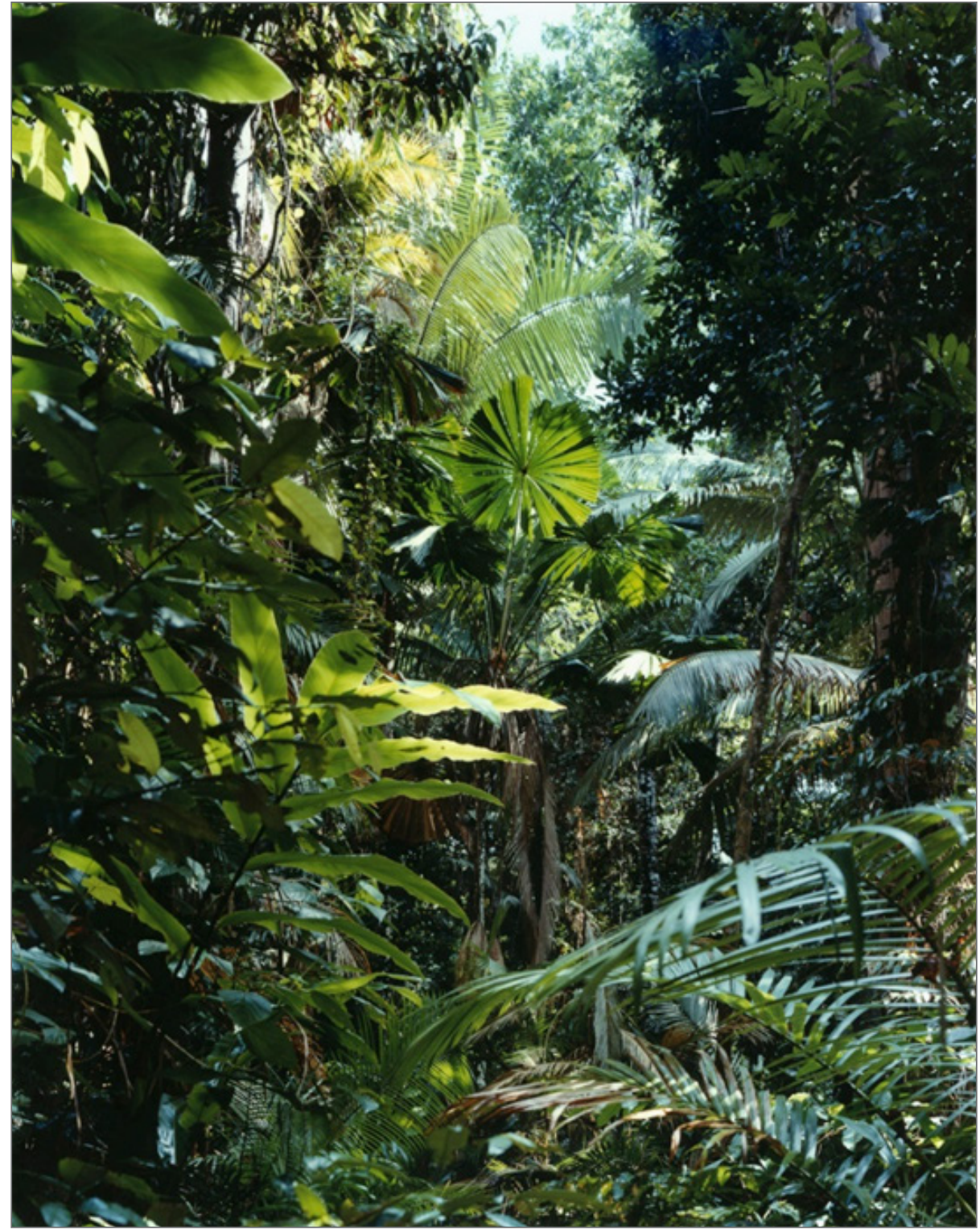

Thomas Struth, Paradise 01, 1998. 
La nostalgia suele ir de la mano del sentimiento de culpa por el menoscabo que la acción humana ha infligido al Edén. Esta actitud se une a una voluntad restitutoria, como sucede en El bosque hueco (2004) obra en la que Lucía Loren rellenó los huecos de los árboles con tejidos vegetales para devolverles simbólicamente aquello que les había sido arrebatado. En otras ocasiones, la reintegración se convierte en un ejercicio arqueológico que rememora el bosque anterior a la presencia humana. Así se muestra en algunas intervenciones de Alan Sonfist, Time Landscape (1965) y Circles of time (1986); en Give and Take Wall (1988), en la que Andy Goldsworthy hizo que el bosque regresase a lo que se había convertido en zona de pasto por la explotación ganadera; en El bosque virgiliano en Fattoria Celle (1985) de lan Hamilton Finlay, que alude al bosque sobre el que se fundó Roma; o en Árboles como arqueología(2003), de Fernando Casás que utiliza la idea de ruina para incidir en el concepto de pérdida.

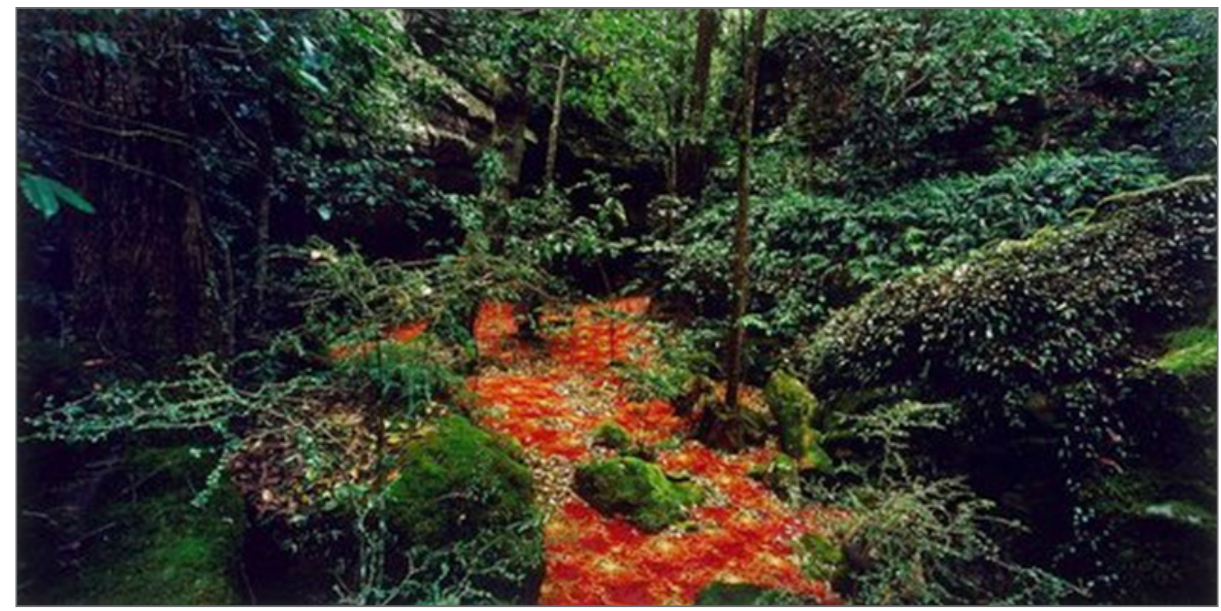

Rosemary Laing, Groundspreed (Red Piazza), 2001.

Otras veces, el regreso al bosque es un intento de recuperar la sacralidad olvidada. Así aparecen, en la obra de lan Hamilton Finlay titulada Five Columnsor Cortot Saint-Just(1982), en la Cattedrale vegetale (2001) de Giuliano Mauri, o en los numerosos santuarios que ha creado Hermann de Vries en las últimas décadas y que se basan en la idea de no intervención. Hay ejemplos en los que se pone el acento en la presencia de lo artificial en cualquier paraje del planeta. Este fue el discurso que Rosemary Laing abordó en Groundspeed (Red Piazza) (2001), unas fotografías en las que se apreciaba un entorno aparentemente salvaje cuyo suelo era una alfombra industrial. Aparecía una naturaleza marginada por la actividad humana con un lenguaje plástico inquietante 
que evidenciaba, al mismo tiempo,la artificialidad y el misterio impenetrable del bosque que solo se puede leer a través de símbolos o imágenes construidos por la cultura.

Alexander Timtschenko o Alex Dorsfman se han sentido fascinados por los espacios artificiales que se recrean en los zoológicos para reproducir visualmente el hábitat de algunos animales o por lo turbadores que resultan las imágenes tomadas de los dioramas de algunos museos de ciencias naturales que, en imágenes escindidas de sus entornos museísticos, parecen más auténticos que los propios bosques. Igual que esas imágenes de espacios salvajes que decoran a diario nuestra vida, un tema que abordó Manuel Sendón en Paisaxes (1989-1991). Estas fotografías que se pueden encontrar en cualquier vivienda particular o en cualquier establecimiento público,reproducen escenas de la vida natural salvaje en las que no aparece el hombre, para componer otra realidad bien distinta.

Así, el bosque del origen se convierte en una elaboración de la imaginación, como en los grafitos de Julio Blancas o las imágenes de Bielowieza que tomó en 2001 Joachim Koester, para investigar el lugar imaginario a través de su realidad material. Bielowieza es la patria primera que polacos, rusos, alemanes o lituanos reclaman como propias, un bosque de la memoria en el que Koester convoca al silencio en el que conviven memoria historia y vegetación, un documento dramático ante el que el espectador no encuentra solución porque es una historia sin historia. Porque el bosque reproduce una situación primitiva, una edad sin memoria, inmóvil que ha escapado del tiempo histórico: "Las edades han pasado sobre él porque él viene de mucho más lejos. Su historia terminó cuando empezaron nuestros anales" (Roupnel 1932, 110-1).

Parece inevitable topar con la noción de paraíso cuando se trata de explicar la historia, decía Emil Cioran en Desgarradura. Esta sería una negación gradual, un distanciamiento paulatino de una situación que resulta tanto convencional como seductora: "kitsch a base de nostalgia", un camino sin retorno dentro de ese tiempo que en occidente se entiende como lineal e irreversible. Al negar la posibilidad de regreso, se sueña con la utopía, con el porvenir que está en el otro extremo de la cuerda temporal que acentúa el carácter bipolar de la relación que los hombres mantienen con la naturaleza. Quizás sea la mítica obra de Joseph Beuys, 7000 robles que presentó en la Documenta VII de Kassel en 1982, la obra que consiguió materializar de forma excepcional una breve utopía en la que el arte actuaba como una herramienta capaz de cambiar el mundo. La obra operaba más allá de la mejora de la ciudad, exigía la puesta 
en práctica de que todo hombre era un artista al tiempo que implicaba a los ciudadanos en una protección activa del medio ambiente al tener que plantar los árboles en la ciudad.

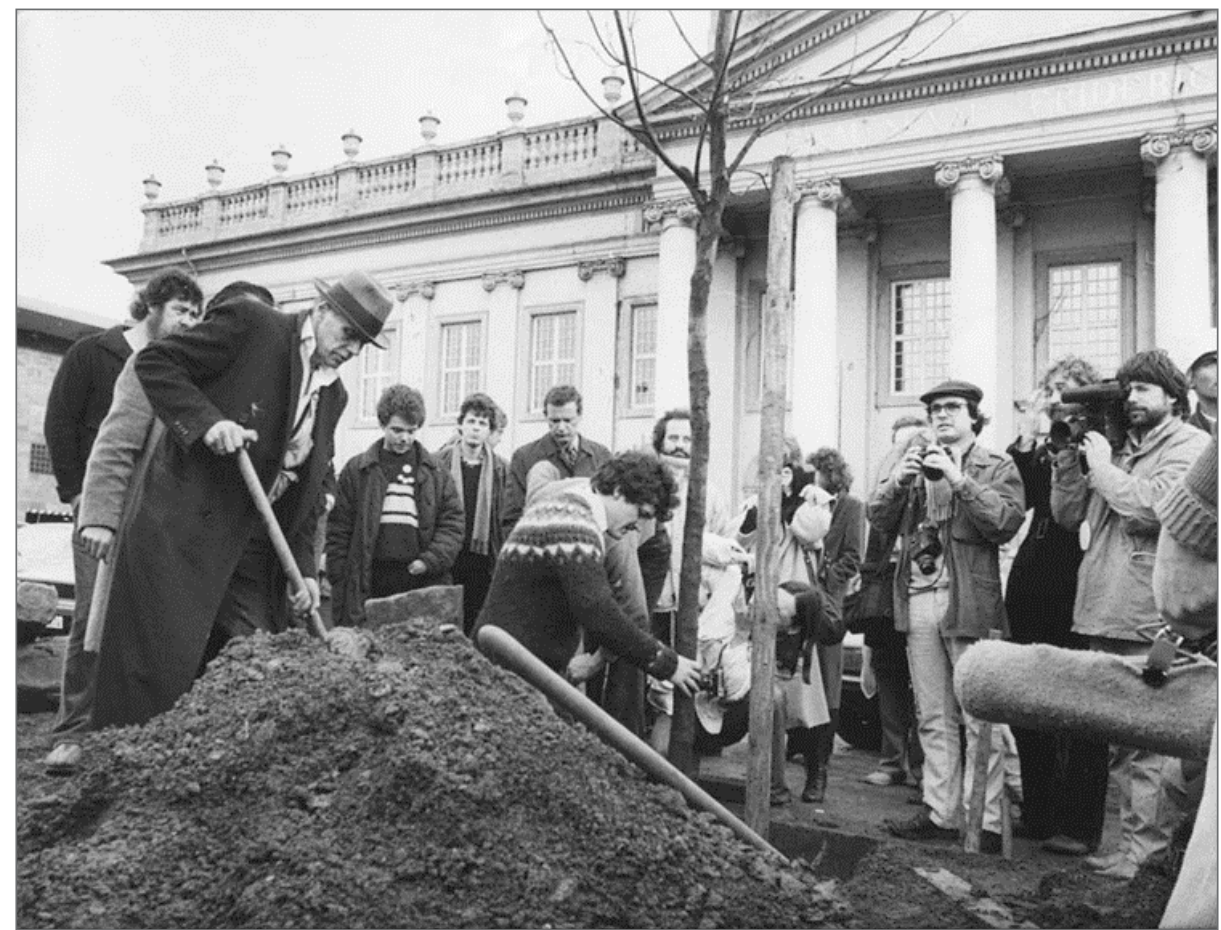

Joseph Beuys, 7000 robles, 1982.

Sin embargo,las fotografías del brasileño Caio Reisewitz son un ejemplo claro de una tensión no resuelta. Unas muestran espacios vírgenes, salvajes, que parece que no existen yotras, como Utopías amenazadas (2005), hacen hincapié en la pugna entre la voracidad de la explotación humana y la selva virgen del territorio brasileño. La utopía de Reiseweitz incide en la magnificencia de un entorno no contaminado y sugiere que esta era incompatible con la presencia humana, con lo que difícilmente esta utopía se refería a un proyecto de perfección colectiva civil. Un trasfondo similar ofrece el grupo finlandés IC-98 desde 2013 con Abendland, una serie de animaciones digitales en las que se imagina el mundo después de la Edad Humana1. Los espacios, oscuros y misteriosos dejan entrever esperanza y cierto alivio ante la desaparición del hombre y el triunfo de la naturaleza en el fin de los tiempos históricos. Las imágenes se suceden en un ambiente en el que se ha silenciado lo humano, 
solo se escucha el sonido de una bandada de pájaros solitarios, el batir suave de las olas del mar y el sordo rumor del bosque.

Los caminos que conducen a la nostalgia o a la utopía tienen en común la manifestación de una profunda tensión con el elemento salvaje que se traduce en angustia y en formas alienadas de mirar el bosque. John Fowles analiza este sentimiento en El árbol (1979) y recurre a la expresión latina Aut Caesar, autnullus para evidenciar lo que considera una trampa heredera del Romanticismo. Si algo no se puede entender completamente, si no puedo ser un verdadero salvaje porque he perdido la selva originaria, ya no quiero tener nada (Fowles 2015, 42). Incluso, si se contempla una imagen boscosa esta ha de trasladar al sujeto a una naturaleza incólume. "The wildness pleases", lo salvaje gusta, es una conocida frase de Shaftersbury que muestra el malestar producido por la civilización y la desesperación de haber perdido el paraíso, un concepto tan incierto como eficaz para funcionar como convencionalismo culposo. Fowles dice que no está en peligro la naturaleza sino nuestra actitud hacia ella. El bosque ni ha desaparecido ni es inaccesible, está ahí pese a los avatares de la historia. Lo que se ha desvirtuado es nuestra manera de acercarnos a él, una forma que niega el descubrimiento individual porque incide en discursos intelectuales codificados de antemano (Fowles 2015, 50). La naturaleza, el bosque y el arte, tienen una faceta de autodescubrimiento y de autoexpresión intransferible que se lleva a cabo de una forma tan desinteresada como lo es el juego para un niño.

A través del proceso del juego se descubre el mundo sin tener que trasladarse a lugares ignotos. El encuentro con lo salvaje está tan a mano como los descampados de las ciudades para sus habitantes. Esos espacios como decía Ignasi de Solà-Morales, llenos de posibilidad que,desde el olvido, elaboran una nueva virginidad selvática. La nueva wilderness, dice Careri(2016, 23), crecida como un bosque desde los despojos de la modernidad. Jeff Wall realizó una serie titulada Foresten el año 2000, en la que mostraba estas espesuras marginales como un lugar en el que se puede volver a empezar. Lara Almárcegui se ha aproximado también a la poética de estas áreas fronterizas en la que el olvido es el sustrato de lo salvaje. Zonas que no encajan en la trama urbana, que son una alternativa alejada del principio de utilidad que rige el pensamiento occidental:"territorios residuales en los que no hay nada: ni pasado, ni futuro, nada que no sea el presente, hecho diagrama, de quienes los cruzan. Espacios también para el juego, porque, pareciendo decrépitos, acaso son en realidad la infancia de todo territorio" (Delgado 2017). 
Otros artistas como Giusepppe Penone, tampoco han sentido la necesidad de trasladarse a lugares remotos, sino que han elegido espacios que les resultaban familiares. Penone, intervino con Alpi Maritimi (1968) en el bosque que estaba al lado de su casa. Del mismo modo que los niños modelan el barro, él dio forma al flujo de la materia del árbol. En Continuera a cresceretranne che in quel punto, una réplica de la mano del artista en bronce abraza un joven árbol que, al crecer, ha envuelto la escultura en un abrazo eterno. También Andy Goldsworthy operaba en lugares cercanos al sitio donde vivía al comienzo de su carrera. En el bosque de Alwoodley realizó algunas de sus primeras obras efímeras, Pine treebentreleased y Brackenthrown, (1976). Tiraba de las ramas de un pino y luego la soltaba o lanzaba helechos sobre las copas de los árboles. Goldsworthy elabora así, a modo de juego, un "lugar practicado" y, las acciones de golpear, arrojar, soltar y saltar se convertían en una manifestación del propio artista dentro del espacio que le rodeaba y vividos en un presente absoluto (Fiske 2007, 27).Un espacio que no se experimenta ni con nostalgia ni con el idealismo imposible de la utopía, que no es, por tanto, ni pasado ni futuro, sino que es presente puro como lo es el descubrimiento. David Hockney regresó hace pocos años a Yorkshire, su tierra natal para pintar sus bosques y colinas al aire libre, para tener también la vivencia de la visión directa del entorno sin ningún tipo de prótesis visual y entregarse al espíritu del lugar sin ideas preconcebidas, y sin exceso de pensamiento, habitando el momento preciso de la creación porque, según apunta el artista, "es el presente lo que es eterno" (Wollheim 2009).

Uno de los juegos predilectos de los niños y que cualquiera ha practicado en la infancia es fabricar una cabaña. Esta es una de las formas habituales de sumergirse en el bosque que muchos han utilizado para practicar una soledad activa en la naturaleza: H. D. Thoreau, T.H. Lawrewnce, Edvard Grieg, Virginia Wolf o Gustav Mahler, son algunos de ellos. Hacer una cabaña es también una de las formas más recurrentes de los creadores que penetran en el bosque. Chris Drury, Patrick Dougherthy, Nils Udo, Giuliano Mauri o Lucía Loren han recurrido a este tipo de estructura en algunas de sus piezas. La cabaña es un espacio de tránsito que permite ir al bosque y volver, que son extraños y familiares al mismo tiempo, que están dentro y fuera del bosque a la vez y definen tanto la esencia de la espesura como la del ser humano. El que construye una cabaña no quiere volver a un estado de semibestialidad sino "enseñar a los hombres a vivir de nuevo, a vivir de otra manera...sobre la tierra" (Duque 2015, $50)$, con conciencia de presente. 
El acceso al paraíso del pasado es imposible y el futuro es incierto. Regodearse en la desazón de no poder volver al estado de naturaleza es tan absurdo como la de imaginar utopías enajenadas de cualquier connotación humana. Es imposible entender el bosque desde esas lindes, al bosque hay que entrar, jugar a perderse dentro y después regresar. El "emboscarse" lleva implícita la intención de mantenerse oculto, como en el juego del escondite. Dentro del bosque uno puede permanecer apostado un tiempo, pero lo que sostiene el placer que produce mantenerse fuera de la vista de los otros es que el que se esconde sabe que esa situación tiene que tener un fina. Los que juegan al escondite saben que tarde o temprano se van a hacer vivibles a los otros, ya sea porque les descubran o porque el escondido decida que llegó el tiempo de abandonar su refugio.

Esconder es preservar, proteger es también un acto creador y fundacional y propicia el descubrimiento de lo oculto. Algo a lo que ha jugado Penone en Ripetereilbosco, acción en la que el artista descubre a golpe de gubia los árboles que se esconden en objetos elaborados por la cultura. Perejaume también gusta de esconderse, uno de sus textos lleva este nombre precisamente, Esconderse (2006) y acompañaba a un vídeo que mostraba personas escondidas entre la vegetación. Esconderse ante el exceso de presencia del hombre y sus obras en el mundo contemporáneo, dejar de hacer y ocultarse para lograr el merecimiento del hacer, para generar lugares habitables y poder escuchar el lenguaje de la naturaleza.

Lars Vilks construyó una obra que recoge muchos de los elementos a los que se han hecho alusión en este breve ensayo. Vilks parece partir de la premisa citada anteriormente y que se refiere a que solo puede manifestarse aquello que ha permanecido oculto. El artista consiguió esconder durante más de dos años una de sus piezas más polémicas, Nimis (lat. "demasiado"). Nimis es una amalgama de viviendas elementales, erigida en la Reserva Natural de Kullaberg, en Suecia y realizada con maderas que el mar había devuelto a la orilla. Al ser descubierta comenzó una larga contienda del gobierno contra Vilks, quien tuvo que pagar algunas multas para que no se derribara la escultura. Después Vilks erigió otras obras que también fueron objeto de polémica con las autoridades. Posteriormente, el 2 de junio de 1996, Lars Vilks junto con otros artistas declararon la independencia ese territorio, designado como Ladonia respecto de Suecia. Ladonia se ha convertido en una performance continua, en un lugar de juego y en una utopía del arte (Blázquez 2006, 174). 


\section{Referencias}

Blázquez Abascal, Jimena et al. 2006. Arte y Naturaleza: Guía de Europa: Parques de esculturas.Editada por Valeria Varas y Raul Rispa.Madrid: Documenta Artes visuales

Careri, Francesco. 2016.Pasear, detenerse. Maurici Pla Serra, trad. Barcelona: Gustavo Gili

Delgado Ruiz, Manuel. 2017. "Breve elogio del descampado: La poética de los terràins vagues". El País, 9 oct. https://elpais.com/elpais/2017/10/06/seres_urbanos/1507276876_392427. $\mathrm{html}$

Duque Pajuelo, Félix.2015. "De cabañas marginales y eremitas intermitentes: Sobre la condición de posibilidad del habitar". En Cabañas para pensar [exposición], un proyecto de Eduardo Outeiro Ferreño; comisariado por Alfredo Olmedo y Alberto Ruiz de Samaniego. Madrid.Maia

Fiske, Tina. 2007. "Andy Golsworthy: «Fui al bosque»".En Andy Goldsworthy (En las entrañas del árbol) [catálogo de exposición] octubre 2007-enero 2008 Palacio de Cristal. Madrid: MNCARS

Fowles, John. 2015. El árbol. Traducción del inglés a cargo de Pilar Adón. Madrid: Impedimenta

OuteiroFerreño, Eduardo. 2015. Cabañas para pensar [exposición]. Comisariado por Alfredo Olmedo y Alberto Ruiz de Samaniego. Madrid.Maia

Perejaume [Pere Jaume Borrell i Guinart]. 2005. Esconderse [Amagar-se]. XV Encuentros de Arte de Sajazarra, textos de Xavier Antich,Perejaume\&Carlos Rosales. Logroño: Gobierno de La Rioja

Roupnel, Gaston. 1932. Histoire de la campagnefrançaise. Paris. Bernard Grasset

Wollheim, Bruno.2009. David Hockney, a bigger picture [vídeo]: An unprecedented documentary portrait of the artist at work. London: Coluga Pictures

\section{Notas}

${ }^{1}$ Abendland significa Occidente, define el lugar del crepúsculo, el punto por que el sol se pone. El camino hacia el Oeste se ha relacionado en numerosas ocasiones con la persecución del paraíso, pues Caín fue desterrado al este del Edén. Y el Oeste es la meta para los colonos norteamericanos que buscaban en occidente la tierra prometida. Durante el mundo antiguo, el occidente fue considerado el confín del mundo, el final de la tierra. En ese punto sitúan los mitos de muchas culturas el mundo de ultratumba, un emplazamiento que se concebía como un lugar ameno. Allí estaban el gran Océano que simbolizaba la inmortalidad y el principio, el Jardín de las Hespérides, los Campos Elíseos, las Islas de los Bienaventurados, o el amplio valle feliz al que partían los indios Comanches después de morir. Lugares de acceso vetado al hombre mortal donde la utopía es realizable precisamente porque el hombre, como tal, ya no está presente. 